\title{
Role of C-Reactive Protein in Development of Hypertension
}

\author{
Mohd Shakeel $^{1}$, Shiv Prakash Rathore ${ }^{2}$, Dharmveer Yadav ${ }^{3}$, Praveen Sharma ${ }^{4}$ \\ ${ }^{1,3}$ Department of Biochemistry, SMS Medical College, Jaipur, Rajasthan, India \\ ${ }^{2}$ Department of Biochemistry, Government Medical College, Kota, Rajasthan, India \\ ${ }^{4}$ AIIMS, Jodhpur, Rajasthan, India
}

\begin{abstract}
Hypertension is one of the most important risk factor for cardiovascular disease and has become an increasingly important contributor to the global health burden. Inflammation and mounting of inflammatory markers (acute phase reactants) are important pathogenic mechanism in development of hypertension. It could be either a causative factor in the pathogenesis of hypertension or a sequel to it. In the view of the probable involvement of the acute phase reactants, present study was planned to investigate role of $C$ reactive protein (CRP) in development of hypertension and find out its correlation with blood pressure if any exist. The study was done at MBS hospital \& New Medical College \& Hospital, Kota. CRP levels in the serum of 50 hyper-tensive cases and 50 healthy sex and age matched control subjects were analysed on Biochemistry Fully auto-analyzer EM-360 by TRANSASIA using standard protocols. Data were analyzed with the help of Microsoft excel 2007, using student's t-test, and strength of association between two variables is measured by Pearson's correlation coefficient (r).CRP level showed a significant positive correlation with systolic blood pressure $(p<0.001)$. So appropriate measures should be taken to bring these parameters in limit for better prognosis and to avoid ill effects of hypertension.
\end{abstract}

Keywords: Acute phase reactants, Cardiovascular disease, C-reactive protein, Systolic blood pressure

\section{Introduction}

Hypertension is one of the most important risk factors for cardiovascular disease and has become an increasingly important contributor to the global health burden $(1,2)$. The estimated total number of adults with hypertension in 2000 was 972 million. Of these, 333 million were estimated to be in economically developed countries and 639 million in economically developing countries. By 2025 , the number of people with hypertension will increase by about $60 \%$ to a total of 1.56 billion as the proportion of elderly people will increase significantly (3). The prevalence of hypertension in India 59.9 and 69.9 per 1000 in males and females respectively in urban population (4) and 35.5 and 35.9 per 1000 in males and females respectively in the rural population (5).

CRP is an acute phase reactant, a marker of inflammation with a half-life of $19 \mathrm{~h}$. CRP has a normal range of $<2 \mathrm{mg} / \mathrm{L}$ in populations without evidence of acute illness; with illnesses such as rheumatoid arthritis or sepsis, and concentrations can increase up to $300 \mathrm{mg} / \mathrm{L}$. Synthesis of CRP occurs in hepatocytes and regulated primarily by interleukin-1, interleukin-6, and tumor necrosis factor- $\alpha$ $(\mathrm{TNF}-\alpha)$. Inflammation and mounting of inflammatory markers are important pathogenic mechanism in development of hypertension (6). Among patients with hypertension, it is well established that pro-inflammatory markers (such as high sensitive C-reactive protein (hs-CRP)) are increased, even after adjustment for potential confounding factors (7). Elevated hs-CRP levels have also been shown to be predictive for the development of hypertension in prehypertensive and normotensive patients $(8,9)$. Howard et al also considered that $\mathrm{C}$-reactive protein levels are associated with future development of hypertension (10).
In a number of cross-sectional studies, patients with essential hypertension showed increased levels of several inflammatory markers, including soluble leukocyte adhesion molecules chemotactic and proinflammatory cytokines specific growth factors heat shock proteins and CD40L(11,12). Some cross-sectional studies reported greater plasma CRP concentrations in treated or untreated patients with hypertension than in normotensive individuals. However, the effects of current or previous antihypertensive treatment and of hypertension duration could not be excluded in those studies. Moreover, in some of these studies, greater plasma CRP concentrations among patients with hypertension might be explained by a clustering of common positive CRP covariates (i.e. age, female sex, increased body mass index and lipid concentrations) among hypertensive patients(13,14). The association between elevated CRP levels and high blood pressure may have three different pathophysiologic explanations (Fig. 1). First, causation may be involved, and indeed several studies hypothesise that CRP may induce a decrease in endothelium dependent relaxation, a potential risk factor for hypertension. Reverse causation might also be implicated, whereby high blood pressure may induce inflammation and raise CRP levels. On the other hand, the association could be explained by confounding, because CRP and high blood pressure share several risk factors such as lower socio demographic position, lack of physical activity, smoking, and abdominal obesity $(15,16)$.In the view of the probable involvement of the acute phase reactants, present study is planned to investigate role of C-reactive protein in development of hypertension.

\section{Material and Method}

Present study was carried out in Department of Biochemistry, Govt. Medical College, Kota, Rajasthan, 


\section{International Journal of Science and Research (IJSR) \\ ISSN (Online): 2319-7064 \\ Index Copernicus Value (2013): 6.14 | Impact Factor (2014): 5.611}

India from June 2012 to Dec. 2012. For this study subjects (males) between 30-60 years of age were selected from the general population of Kota district and screened for hypertension. Hypertension was defined as a reading of $\geq 140 / 90 \mathrm{mmHg}$ on three consecutive measurements at least six hours apart. Subjects were distributed on the basis of increasing blood pressure in 2 groups of hypertensive (case) and non-hypertensive (control). Each group comprised of 50 subjects.

All the subjects had undergone through a complete physical examination. Socio-economic status of every individual was assessed by living standard and monetary status. The family history regarding obesity, diabetes, hypertension, coronary artery disease (CAD) was carefully recorded by a questionnaire and subjects with CAD, C.O.P.D., Rheumatoid Arthritis, Gastro-intestinal or Renal disorder, acute or chronic inflammatory conditions were excluded. Complete physical examination and clinical history of subjects were also recorded.

After overnight fasting, venous blood of the subjects was drawn from antecubital vein using aseptic techniques. Samples were collected in plain vial. They were left standing for one hour and serum was separated. Serum was analyzed for estimation of C-reactive protein levels, using standard protocol on TRANSASIA EM-360 auto-analyzer. CRP concentration does not have any diurnal variations and is unaffected by eating; hence, it can be estimated in a nonfasting blood sample. Results were expressed as Mean \pm SD. Data were analyzed with the help of Microsoft excel 2007, using Student's t- test, and strength of association between two variables was measured by Pearson's correlation coefficient (r).

\section{Result}

The mean serum CRP levels were significantly higher in patients with hypertension compared with control group of healthy subjects $(17.27 \pm 12.24 \mathrm{mg} / 1$ versus $8.28 \pm 5.78 \mathrm{mg} / 1$, $\mathrm{p}<0.0001$ ). (Fig.1). CRP level showed a significant positive correlation( $(\mathrm{r}=0.43)$ with systolic blood pressure.(Fig.2)

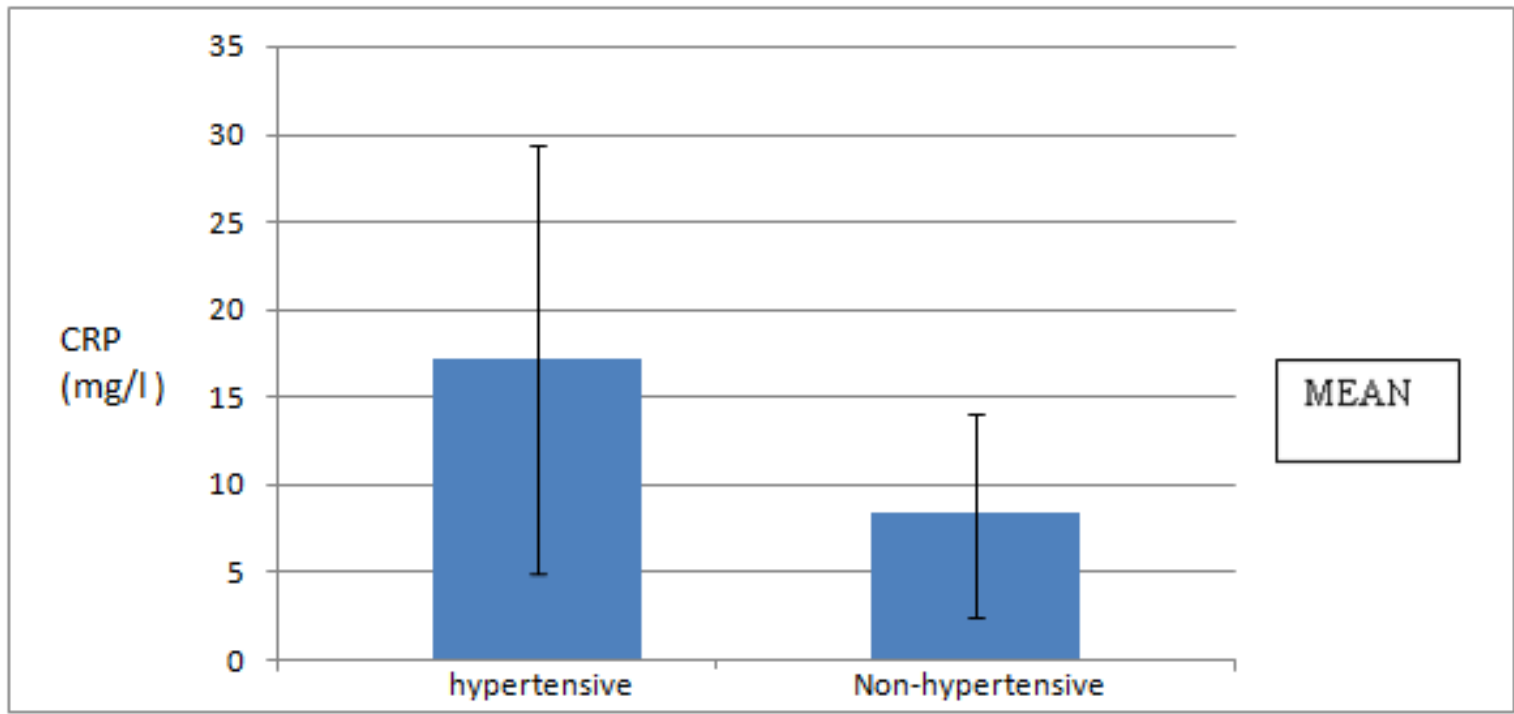

Figure 1: Comparison of C-reactive protein in Hypertensive and Non-hypertensive subjects

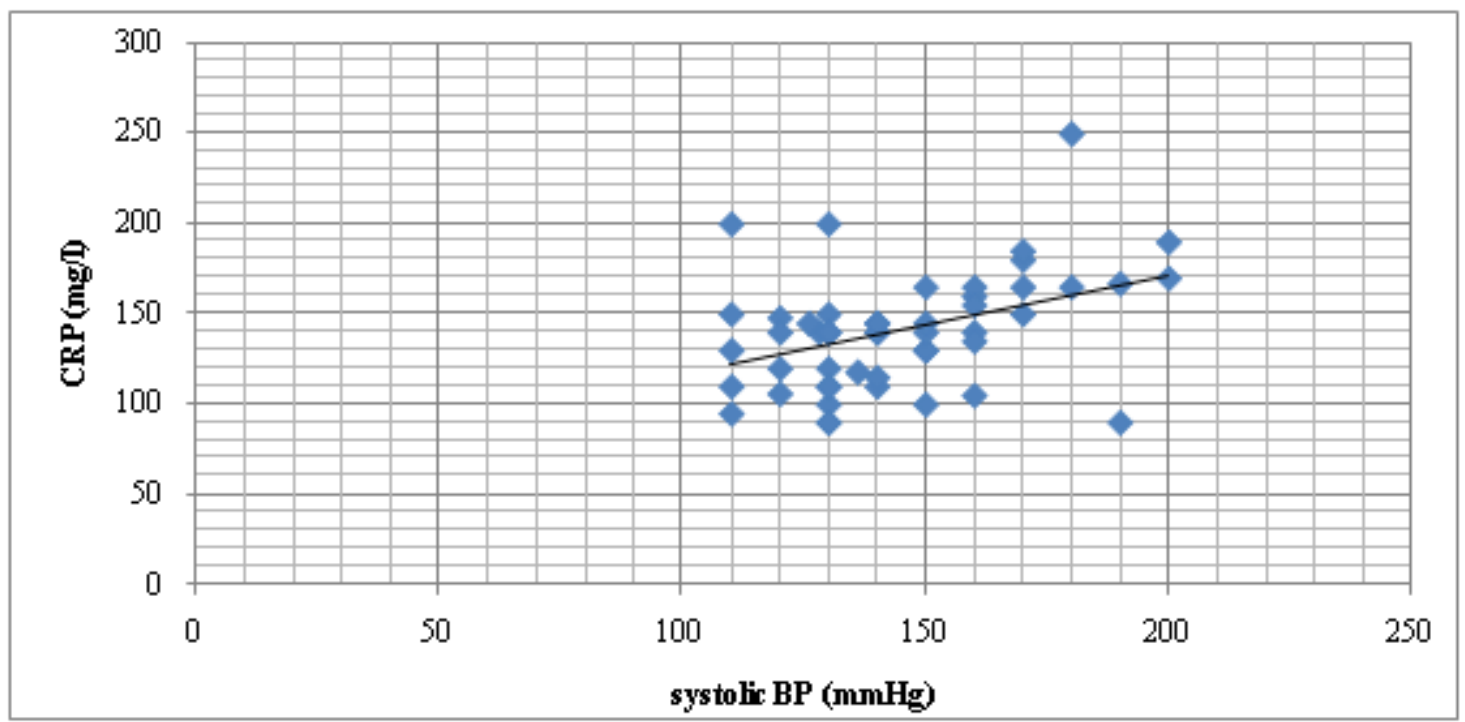

Figure 2: Correlation of CRP with systolic blood pressure 


\section{International Journal of Science and Research (IJSR) \\ ISSN (Online): 2319-7064 \\ Index Copernicus Value (2013): 6.14 | Impact Factor (2014): 5.611}

\section{Discussion}

This study provides evidence supporting low-grade inflammation as part of the "common soil" leading to development of the metabolic syndrome, diabetes and cardiovascular disease and hypertension which is a integral part of metabolic syndrome. There are data indicating that elevated hs-CRP levels predict development of the metabolic syndrome. Metabolic syndrome is a cluster of cardio metabolic risk factors. It is frequently associated with an acute phase reaction, suggestive of a low grade inflammatory status of vascular endothelium. In fact the markers of acute phase response, including serum amyloid A, CRP and IL-6, the main mediator of the response, have been shown to be elevated in patients with metabolic syndrome.

Serum CRP is an acute phase reactant protein (APR) synthesized by hepatocytes under the influence of interleukin-1 originating at sites of inflammation and trauma (17). It has been shown to be beneficial in the clinical evaluation of cardiovascular disorder in adults. CRP and blood pressure are independent determinants of cardiovascular risk, and their predictive value is additive (18). CRP \& other APRs like fibrinogen are important positive APRs mounting of which may contribute to hypertension. (10,19). Recently, chronic low- grade inflammation has been identified as an integral part in the pathogenesis of vascular disease. The presence of inflammatory markers like C-reactive protein, fibrinogen, TNF- $\alpha$, IL- 6 within the body can have a significant role in the generation and progression of many disease processes like CVD, cerebrovascular accident, and diabetic complications.

The present study was conducted on 100 subjects to evaluate the role of C-reactive protein in development of hypertension. Subjects were distributed on the basis of increasing blood pressure in two groups of non-hypertensive and hypertensive. In this study, it was observed that hypertensive subjects had significantly elevated level of serum CRP as compare to non-hypertensive, supporting the earlier studies which state that CRP is associated with future development of hypertension. (10). It is proven fact that a link between hypertension and inflammation has been established in many research works (20). The present study provide evidence for a critical role of inflammation in the development of hypertension, the mechanisms of this effect are uncertain and require further evaluation. The measurement of CRP may provide additional prognostic information as an adjunct for global risk assessment in patients with hypertension. Further studies involving greater number of patients are needed to clarify the causal relationship between raised CRP levels in predicting the severity of hypertension.

\section{Conclusion}

CRP is a critical determinant of the exaggeration of cardiovascular disorders, including hypertension and metabolic disorders, not merely as a simple biomarker of these disease states, it is important to further examine the details of the signaling mechanism of CRP mediated inflammation and oxidative stress and specific target organs of CRP and the localization of CRP receptors to understand the roles of CRP in the pathogenesis of metabolic syndrome and cardiovascular disease and to develop clinical interventions against CRP-mediated effects. So it is recommended that CRP estimation should be done in evaluation and prognostication of all hypertensive patients.

\section{References}

[1] He, FJ., and MacGregor, GA. "Cost of poor blood pressure control in the UK: 62,000 unnecessary deaths per year," J. Hum. Hypertens. 2003; 17: 455-7.

[2] Ezzati M, Lopez AD, Rodgers A, Vander Hoorn S, Murray CJ. "Comparative Risk Assessment Collaborating Grou-p. Selected major risk factors and global and regional burden of disease" Lancet 2002; 360: $1347-60$

[3] Kearney PM, Whelton M, Reynolds K, Muntner P, Whelton PK, He J. "Global burden of hypertension: analysis of worldwide data" Lancet 2005; 365: 217-23.

[4] Gupta, SP., Siwach, SB., and Moda, VK. "Epidemiology of hypertension based on total community survey in the ur-ban population of Haryana" Indian Heart J. 1978; 30(6): 315-22.

[5] Gupta, SP., Siwach, SB., and Moda, VK. "Epidemiology of hypertension based on total community survey in the ru-ral population of Haryana" Indian Heart J. 1977; 29: 53-62.

[6] Kaptoge S, Di Angelantonio E, Lowe G, Pepys MB, Thompson SG, Collins R et al. "Emerging Risk Factors Collab-oration: C-reactive protein concentration and risk of coronary heart disease, stroke, and mortality: an individual participant me-ta-analysis" Lancet 2010; 375: 132-40.

[7] Bautista, LE. "Inflammation, endothelial dysfunction, and the risk of high blood pressure: epidemiologic and biolog-ical evidence" J. Hum. Hypertens. 2003; 17: 223-30.

[8] Chrysohoou C, Pitsavos C, Panagiotakos DB, Skoumas J, Stefanadis C. "Association between prehypertension statu-s and inflam-matory markers related to atherosclerotic disease: The ATTICA Study" Am. J. Hypertens. 2004; 17: 568- 73.

[9] King DE, Egan BM, Mainous AG 3rd, Geesey ME. "Elevation of Creactive protein in people with prehypertension" J. Clin. Hypertens. 2004; 6(10): $562-$ 8.

[10]Howard, D. "C-Reactive Protein and the Risk of Developing Hypertension” JAMA 2003; 290(22): 294551.

[11] Parissis JT, Korovesis S, Giazitzoglou E, Kalivas P, Katritsis D. Plasma profiles of pe-ripheral monocyterelated i-nflammatory markers in patients with arterial hypertension. Co-rrelations with plasma endothelin-1. Int J Cardiol. 2002; 83: 13-21.

[12]Ferri C, Desideri G, Baldoncini R, Bellini C, De Angelis C, Mazzocchi C et al. Early activation of vascular endot-helium in nonobese, nondiabetic essential hypertensive patients with multiple metabolic abnormalities. Diabetes 1998; 47: 660-7.

[13] Pockley AG, De Faire U, Kiessling R, Lemne C, Thulin T, Frostegard J. Circulating heat shock protein and heat shock protein antibody levels in established hypertensi- 


\section{International Journal of Science and Research (IJSR) \\ ISSN (Online): 2319-7064}

Index Copernicus Value (2013): 6.14 | Impact Factor (2014): 5.611

on. J Hypertens 2002; 20: 1815-20.

[14] Yan JC, Ma GS,WuZG, Kong XT, Zong RQ, Zhan LZ. Increased levels of CD40-CD40 ligand system in patients with essential hypertension. Clin Chim Acta 2005; 355: 191-6.

[15] Bautista LE, Vera LM, Arenas IA, Gamarra G. Independent association between inflammatory markers (C-reactiv-e protein, interleukin-6, and TNF-alpha) and essential hypertension. J Hum Hypertens 2005; 19: 14954.

[16] Pepys MB, Hirschfield GM. C-reactive protein: a critical update. J Clin Invest 2003; 111: 1805-12.

[17] Chensue SW, Davey MP, Remick DG, Kunkel SL. "Release of Interleukin-I by Peripheral blood mononuclear cell-s in patient with tuberculosis and active inflammation" Infection and Immunity 1986; 52(1): 341-3.

[18] Gavin J. Blake, Nader Rifai, Julie E. Buring, Paul M Ridker. "Blood Pressure, C-Reactive Protein, and Risk of Fu-ture Cardiovascular Events" Circulation 2003; 108(24): 2993-9.

[19] Anoop Shankar, Jie Jin Wang, Elena Rochtchina and Paul Mitchell. "Positive Association Between Plasma Fibrin-ogen Level and Incident Hypertension Among Men: Population-Based Cohort Study" Hypertension 2006; 48(6): 1043-9.

[20] Christopher, J., and Gregory, Y. H. "Is Hypertension an Inflammatory Process" Current Pharmaceutical Design 2006; 12(13): 1623-35. 